\title{
Isolation and Characterization of Nanobodies against a Zinc-Transporting P-Type ATPase
}

\author{
Elena Longhin ${ }^{1} \mathbb{D}$, Christina Gronberg ${ }^{1,+}$, Qiaoxia $\mathrm{Hu}^{1,+}{ }^{+}$, Annette Susanne Duelli ${ }^{1}$, \\ Kasper Røjkjær Andersen $2, * \mathbb{B}$, Nick Stub Laursen ${ }^{2}$ and Pontus Gourdon 1,3,* \\ 1 Department of Biomedical Sciences, University of Copenhagen, Blegdamsvej 3B, DK-2200 Copenhagen, \\ Denmark; elonghin@sund.ku.dk (E.L.); christina.groenberg@sund.ku.dk (C.G.); qiaoxia@sund.ku.dk (Q.H.); \\ duelli@sund.ku.dk (A.S.D.) \\ 2 Department of Molecular Biology and Genetics, Aarhus University, Gustav Wieds Vej 10c, \\ DK-8000 Aarhus C, Denmark; nsl@mbg.au.dk \\ 3 Department of Experimental Medical Science, Lund University, Sölvegatan 19, SE-221 84 Lund, Sweden \\ * Correspondence: kra@mbg.au.dk (K.R.A.); pontus@sund.ku.dk (P.G.); Tel.: +45-2095-5917 (K.R.A.); \\ +45-5033-9990 (P.G.) \\ + These authors contributed equally to this work.
}

Received: 17 October 2018; Accepted: 4 November 2018; Published: 7 November 2018

\begin{abstract}
P-type ATPases form a large and ubiquitous superfamily of ion and lipid transporters that use ATP (adenosine triphosphate) to carry out their function. The IB subclass ( $\mathrm{P}_{\text {IB }}$-ATPases) allows flux of heavy metals and are key players in metal detoxification, critical for human health, crops, and survival of pathogens. Nevertheless, $\mathrm{P}_{\mathrm{IB}}$-ATPases remain poorly understood at a molecular level. In this study, nanobodies ( $\mathrm{Nbs}$ ) are selected against the zinc-transporting $\mathrm{P}_{\mathrm{IB}}$-ATPase ZntA from Shigella sonnei (SsZntA), aiming at developing tools to assist the characterization of the structure and function of this class of transporters. We identify six different $\mathrm{Nbs}$ that bind detergent stabilized SsZntA. We further assess the effect of the Nbs on the catalytic function of SsZntA, and find that five nanobodies associate without affecting the function, while one nanobody significantly reduces the ATPase activity. This study paves the way for more refined mechanistical and structural studies of zinc-transporting $\mathrm{P}_{\mathrm{IB}}$-ATPases.
\end{abstract}

Keywords: P-type ATPase; nanobody; llama; Zinc-transport; Zinc-transporting P-ATPase; ZntA

\section{Introduction}

The protein superfamily of P-type ATPases is formed by phylogenetically related pumps that actively transport ions and lipids across biological membranes of prokaryotes and eukaryotes [1] at the expense of adenosine triphosphate (ATP). They are divided in five subfamilies $\left(\mathrm{P}_{\mathrm{I}}-\mathrm{P}_{\mathrm{V}}\right)$ based on sequence similarity and transport specificity [2]. $\mathrm{P}_{\mathrm{I}}$-ATPases transport cations, with the $\mathrm{P}_{\mathrm{IB}}$-subclass being specific for heavy metals such copper and zinc. Noteworthy members of the other subfamilies include the calcium and sodium-potassium ATPases of $\mathrm{P}_{\mathrm{II}}$ and the proton ATPase of $\mathrm{P}_{\mathrm{III}}$. The focus here is on class $2 \mathrm{P}_{\mathrm{IB}}$-ATPases, $\mathrm{P}_{\mathrm{IB}-2}$-ATPases, which comprises zinc-transporting P-type ATPases. These ATPases are relatively poorly characterized from a mechanistic and functional point of view, and only E2 states (metal-free) have been resolved structurally [3]. One reason is that metals such as zinc render these targets unstable, and another that there are no identified compounds that can bind specifically and exclusively to several specific states (including metal bound E1 conformations) of $\mathrm{P}_{\mathrm{IB}}$-ATPases. The overall structural architecture is conserved in all P-type ATPases, with four domains [4]: The soluble domains, P (phosphorylation), N (nucleotide binding), and A (actuator), and the $\mathrm{M}$ domain in the transmembrane region. The $\mathrm{P}$ domain contains the highly conserved 
aspartic acid-lysine-threonine-glycine-threonine (DKTGT) motif with the catalytic aspartate that is targeted by ATP stimulated autophosphorylation. The $\mathrm{N}$ domain is responsible for orienting the ATP towards the P domain. The A domain comprises the conserved threonine-glycine-glutamic acid (TGE) loop, which allows for dephosphorylation of the catalytic aspartate in the P-domain and the $\mathrm{M}$-domain is composed by a variable number of helices that enclose membranous ion-binding site(s) that are critical for transport. In addition, zinc transporting $\mathrm{P}_{\mathrm{IB}-2}$-ATPases possess one or more soluble subfamily-specific domains known as heavy metal-binding domains (HMBDs), whose function remains unclear [5]. These domains work in a tightly coupled manner in order to achieve transport, and the reaction cycle is summarized in the so called Post-Albers scheme [6-8] (Figure 1).

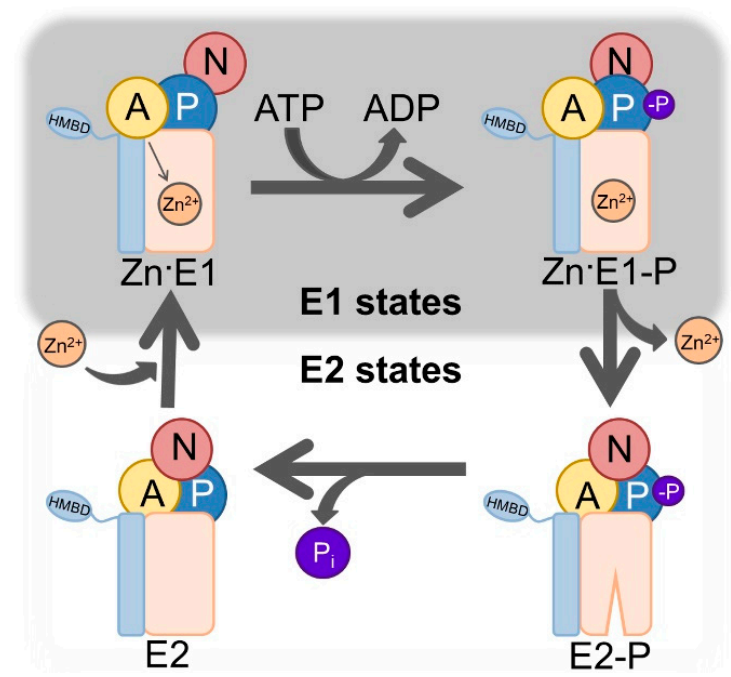

Figure 1. Post-Albers scheme of $\mathrm{P}_{\mathrm{IB}-2}$-ATPases. The E1 (high zinc affinity) and E2 (low zinc affinity) states of the enzyme alternate, and couple ATP (adenosine triphosphate) hydrolysis to the export of zinc. The E1 state accepts one zinc $\left(\mathrm{Zn}^{2+}\right)$ ion and ATP from the intracellular side, which promotes autophosphorylation, reaching the zinc occluded Zn·E1-P state and releasing ADP (adenosine diphosphate). Completion of phosphorylation triggers considerable conformational changes that opens the pump towards the outside, allowing release of zinc in the E2-P state. Metal discharge is associated with auto dephosphorylation, liberation of inorganic phosphate $\left(\mathrm{P}_{\mathrm{i}}\right)$, and allows the enzyme to reach the E2 conformation. The domains are represented as follows: The actuator (A) domain in yellow, the phosphorylation $(\mathrm{P})$ domain in blue, the nucleotide-binding $(\mathrm{N})$ domain in red, the transmembrane domain in light orange. Features specific for $\mathrm{P}_{\mathrm{IB}}$-ATPases are shown in light blue, and includes two transmembrane helices and heavy-metal binding domain(s) (HMBD).

Antibodies, or immunoglobulins, are large plasma proteins that play a fundamental role in protection against pathogens, such as microorganisms, and are used for numerous basic and applied science applications. Immunoglobulin gamma 1 (IgG1), which is the most abundant immunoglobulin, comprises four polypeptide chains: Two heavy chains, each formed by a variable domain $\left(\mathrm{V}_{\mathrm{H}}\right)$ and three constant domains $\left(\mathrm{C}_{\mathrm{H}} 1, \mathrm{C}_{\mathrm{H}} 2\right.$, and $\left.\mathrm{C}_{\mathrm{H}} 3\right)$, and two light chains, composed by a variable $\left(V_{L}\right)$ and a constant $\left(C_{L}\right)$ domain. The paratope (antigen binding-site) is formed by the $V_{L}$ and $V_{H}$ domains and mediates the interaction with the antigen [9]. However, heavy-chain only antibodies are present in certain species [10]: They are smaller (about $75 \mathrm{kDa}$ ) than other antibody isotypes and are formed by two heavy chains, each containing a $\mathrm{V}_{\mathrm{HH}}, \mathrm{C}_{\mathrm{H}} 2$, and $\mathrm{C}_{\mathrm{H}} 3$ domain. Their paratope permits antigen-recognition despite being formed by a single $\mathrm{V}_{\mathrm{HH}}$ domain only, paving the way for the development of single-domain antibodies also called nanobodies. These engineered antibodies are derived from such heavy-chain only antibodies and consist of a single polypeptide chain (about $13 \mathrm{kDa}$ ) folding into a variable domain $\left(\mathrm{V}_{\mathrm{HH}}\right)$. They can be obtained by immunization of camelids (e.g., llamas) with the target antigen, followed by generation of phage display libraries and screening for antigen binding [11]. 
The aim of this work is to isolate nanobodies $(\mathrm{Nbs})$ that selectively associate with the zinc-transporter, ZntA, from Shigella sonnei (SsZntA), the target employed previously for structural characterization of $\mathrm{P}_{\mathrm{IB}-2}$-ATPases [3], to develop inhibitors for further structural and functional studies. We successfully raise and purify $\mathrm{Nbs}$ against SsZntA and perform experiments to assess binding and inhibition capacities. Notably, we identify six Nbs, which bind specifically to SsZntA, including one that exhibits an inhibitory effect on the ATPase activity.

\section{Materials and Methods}

\subsection{SsZntA Production}

In the following text we refer to the manufacturers Sigma-Aldrich with location in Schnelldorf, Germany; and to VWR with location in Søborg, Denmark, unless other is stated. The gene for ZntA from the bacterium Shigella sonnei (UniProtID Q3YW59) was cloned in the vector, pET22 (Merck, Novagen ${ }^{\circledR}$, Darmstadt, Germany), containing an amino-terminus tag of eight histidine residues (HisTag) for downstream affinity chromatography purification and a cleavage site for TEV protease (TEVp) to allow removal of the HisTag. The construct, pET22-HisTag-SsZntA, was transformed into the E. coli C43(DE3) expression strain and cells were grown in Terrific-Broth medium (12\% peptone (Sigma-Aldrich), $24 \%$ yeast extract (Sigma-Aldrich), 4\% glycerol (VWR), $50 \mathrm{mM}$ Phosphate buffer $\mathrm{pH} 7$ (VWR)) at $37^{\circ} \mathrm{C}$ until OD600 reached 1 . Then, protein production was induced with $1 \mathrm{mM}$ isopropyl- $\beta$-D-thiogalactoside (IPTG) (Biosynth AG, Staad, Switzerland) at $18{ }^{\circ} \mathrm{C}$ for $24 \mathrm{~h}$. Cells were harvested at $8000 \times g$ for $15 \mathrm{~min}$, and resuspended at a concentration of $5 \mathrm{~mL} / \mathrm{g}$ wet cells in buffer containing $50 \mathrm{mM}$ Tris- $\mathrm{HCl} \mathrm{pH}$ 8 (Sigma-Aldrich), $200 \mathrm{mM} \mathrm{KCl}$ (VWR), 20\% v/v glycerol (VWR), $5 \mathrm{mM} \beta$-mercaptoethanol (BME) (VWR), 1 SIGMAFAST ${ }^{\mathrm{TM}}$ protease inhibitor tablet (Sigma-Aldrich) per $6 \mathrm{~L}$ culture, and then stored at $-20{ }^{\circ} \mathrm{C}$. To the thawed cells, a final concentration of $1 \mathrm{mM} \mathrm{MgCl}$ (VWR), $2 \mu \mathrm{g} / \mathrm{mL} \mathrm{DNase} \mathrm{I}$ (Sigma-Aldrich) and $1 \mathrm{mM}$ phenylmethanesulphonyl fluoride (PMSF) (Sigma-Aldrich) were added before lysis. The solution was passed through a Constant Systems cell disruptor (Constant Systems Limited, Daventry, UK) twice at $25 \mathrm{kpsi}$, large cell debris were spun down at 20,000× $g$ for $40 \mathrm{~min}$, and membranes were isolated by ultracentrifugation at $190,000 \times g$ for $3 \mathrm{~h}$. The membrane pellet was resuspended in $20 \mathrm{mM}$ Tris- $\mathrm{HCl} \mathrm{pH} 7.5,200 \mathrm{mM} \mathrm{KCl}, 20 \% v / v$ glycerol, $1 \mathrm{mM} \mathrm{MgCl} 2,5 \mathrm{mM} \mathrm{BME \text {, }}$ $1 \mathrm{mM}$ PMSF at $3 \mathrm{mg}$ (total protein) per mL (buffer), and solubilized in 1\% $w / v$ n-Dodecyl- $\beta$-D-maltoside (DDM) (Anatrace, Maumee, OH, USA) for $1.5 \mathrm{~h}$, followed by ultracentrifugation at 190,000× $g$ for $45 \mathrm{~min}$ to remove insolubilized material. The supernatant from $6 \mathrm{~L}$ culture was adjusted to $50 \mathrm{mM}$ imidazole (Sigma-Aldrich) and $500 \mathrm{mM} \mathrm{KCl}$ prior to loading on a $5 \mathrm{~mL}$ HisTrap HP (GE Healthcare, Life Sciences, Uppsala, Sweden) equilibrated in buffer containing $20 \mathrm{mM}$ Tris- $\mathrm{HCl}$ pH 7.5, $200 \mathrm{mM} \mathrm{KCl}$, $20 \%$ v/v glycerol, $1 \mathrm{mM} \mathrm{MgCl} 2,0.015 \%$ w/v octaethylene glycol monododecyl ether $\left(\mathrm{C}_{12} \mathrm{E}_{8}\right)(\mathrm{Nikko}$ Chemicals Co., Ltd., Tokyo, Japan), $5 \mathrm{mM}$ BME, using an Äkta pure chromatographic system (GE Healthcare, Life Sciences, Uppsala, Sweden), and was eluted with the same buffer with $500 \mathrm{mM}$ imidazole added. Protein containing fractions were pooled and treated with TEVp to remove the HisTag while dialyzing to diminish the excess of imidazole. The cleaved sample was loaded on the HisTrap again (Reverse-affinity chromatography or R-IMAC) to separate uncleaved (HisTagged) protein and the TEVp; the flow through was collected and tested by Western-blot using a conjugated antibody against $6 \times$ HisTag $\left(6 \times\right.$ His mAb-HRP conjugated by Takara ${ }^{\circledR}$ Bio Europe AB, Göteborg, Sweden) to assess cleavage. The cleaved sample was concentrated to $12 \mathrm{mg} / \mathrm{mL}$ and run on a $24 \mathrm{~mL}$ size-exclusion chromatography (SEC) column with Superose6 beads (GE Healthcare, Life Sciences, Uppsala, Sweden) equilibrated in SEC buffer (20 mM MOPS (3-(N-morpholino)propanesulfonic acid) (VWR) pH 6.8, $80 \mathrm{mM} \mathrm{KCl,} \mathrm{20 \%} \mathrm{v/v}$ glycerol, $3 \mathrm{mM} \mathrm{MgCl} 2,0.03 \% w / v$ DDM or $0.015 \% w / v \mathrm{C}_{12} \mathrm{E}_{8}, 5 \mathrm{mM} \mathrm{BME}$ ). The fractions corresponding to the main peak were collected, assessed for purity by SDS-PAGE (sodium dodecyl sulfate-polyacrylamide gel electrophoresis) (Thermo Fisher Scientific, Roskilde, Denmark), concentrated to $10 \mathrm{mg} / \mathrm{mL}$, and stored at $-80{ }^{\circ} \mathrm{C}$. 


\subsection{LpCopA and MmCadA Production}

CopA from Legionella pneumophila (LpCopA, UniProtID Q5ZWR1) and CadA from Mesorhizobium metallidurans (MmCadA, UniProtID I4IY19) were produced with the same buffers as SsZntA, but with somewhat different approaches. LpCopA was cloned in the pET22 vector, without any affinity chromatography tag nor cleavage site, and was purified by $\mathrm{Ni}^{2+}$-affinity chromatography exploiting the endogenous histidine rich amino-terminus (no engineered HisTag). MmCadA was cloned in the pET52 vector (Merck, Novagen ${ }^{\circledR}$, Darmstadt, Germany) that includes an N-terminal Strep-tag II with a HRV 3 C cleavage site and was purified by StrepTactin ${ }^{\circledR}$ Superflow ${ }^{\circledR}$ (IBA GmbH, Göttingen, Germany) [12] affinity chromatography at $\mathrm{pH} 7.8$, followed by SEC at $\mathrm{pH}$ 7.4; this tag does not bind metal ions and therefore does not need to be removed.

\subsection{Llama Immunization and Nanobodies Identification}

Llama immunization and library generation was performed as previously described, now using a mixture of proteins including purified SsZntA for immunization [13]. Briefly, SsZntA solubilized in $0.03 \% w / v$ DDM were injected four times $(100 \mu \mathrm{g} /$ injection) during a period of 12 weeks. The immunization was performed under the permit of Capralogics Inc., which provides a healthy housing environment for all animals and adheres strictly to the United States Department of Agriculture Animal Welfare Act regulations for Animal Care and Use. Peripheral blood mononuclear cells (PMBCs) were isolated with Ficoll paque plus (GE healthcare, Life Sciences, Uppsala, Sweden), and total RNA were extracted using a RNeasy plus kit (Qiagen, Hilden, Germany). cDNA was generated with Superscript III first strand (Invitrogen) and amplified using primers specific for the VHH genes. PCR products were cloned into a phagemid vector designed to express $\mathrm{Nbs}$ as pIII fusions and with a C-terminal E-detection tag. VCSM13 helper phages were used for generation of a M13 phage-display library. For selection, $20 \mu \mathrm{g}$ biotinylated SsZntA (solubilized in $0.015 \% \mathrm{w} / \mathrm{v}$ $\mathrm{C}_{12} \mathrm{E}_{8}$ ) bound to streptavidin beads were blocked in SEC buffer (containing $0.015 \% w / v \mathrm{C}_{12} \mathrm{E}_{8}$ and supplemented with $2 \% w / v$ bovine serum albumin (BSA) (Sigma-Aldrich) for $30 \mathrm{~min} .5 \times 10^{13} \mathrm{M} 13$ phage particles were incubated with the protein for $1 \mathrm{~h}$ before the beads were washed 15 times with SEC buffer (with $0.015 \% w / v \mathrm{C}_{12} \mathrm{E}_{8}$ ). Elution of the bound phage particles were achieved by addition of $500 \mu \mathrm{L}$ of $0.2 \mathrm{M}$ glycine (Sigma-Aldrich) pH 2.2 for $10 \mathrm{~min}$, which were added to $75 \mu \mathrm{L}$ of $1 \mathrm{M}$ Tris $\mathrm{pH} 9.1$ for neutralization before being added to E. coli ER2738 cells. Cells were incubated for $1 \mathrm{~h}$ at $37{ }^{\circ} \mathrm{C}$ and plated on agar plates with $2 \% w / v$ glucose (Sigma-Aldrich). The enriched library was amplified and used in a second round of phage display performed as the first round, but with $1 \mu \mathrm{g}$ SsZntA and $2 \times 10^{12}$ M13 phage particles. For ELISA, single colonies were transferred to a 96-well plate format and grown for $4 \mathrm{~h}$ in LB medium, before $\mathrm{Nb}$ production was induced by addition of IPTG to $0.8 \mathrm{mM}$. The plate was incubated by shaking overnight at $30^{\circ} \mathrm{C}$. Next, the plate was centrifuged and $50 \mu \mathrm{L}$ of the supernatant was transferred to an ELISA plate coated with a total of $50 \mu \mathrm{g}$ SsZntA in SEC buffer (with $0.015 \% w / v \mathrm{C}_{12} \mathrm{E}_{8}$ ) blocked with $2 \% w / v$ BSA. After incubation for $1 \mathrm{~h}$, the plate was washed four times with SEC buffer (with $0.015 \% w / v \mathrm{C}_{12} \mathrm{E}_{8}$, without BME), and the anti-E-tag-HPR antibody (Bethyl Laboratories Inc., Montgomery, TX, USA) was added. The plate was then washed four times in SEC buffer (with $0.015 \% w / v \mathrm{C}_{12} \mathrm{E}_{8}$, without BME) followed by the addition of $50 \mu \mathrm{L}$ $3,3^{\prime}, 5,5^{\prime}$-tetramethyl-benzidine (Sigma-Aldrich). The reaction was quenched by addition of $50 \mu \mathrm{L}$ of $1 \mathrm{M} \mathrm{HCl}$ and absorbance was measured at $450 \mathrm{~nm}$. Positive phagemids were sequenced and subcloned in pET22, containing a PelB signal at the amino-terminus for periplasmic secretion and a 6xHisTag at the carboxyl-terminus.

\subsection{Nanobodies Sequence Analysis}

ELISA-identified $\mathrm{Nb}$ hits were sequenced and the obtained sequences were aligned using the SeaView software (version 4.7, PRABI-Doua, Lyon, France) [14], and a phylogenetic tree was built using the BLOSUM62 matrix. The aligned sequences were visualized using the Sequence Manipulation 
Suite@ (Multiple Align Show) (version 2, Paul Stothard, University of Alberta, Edmonton, NA, Canada) [15] to highlight the level of identity with a threshold of $90 \%$, which allowed selection of non-redundant Nbs for downstream efforts. The predicted secondary structure was obtained combining the predictions from ABody Builder Antibody Modelling software (Oxford Protein Informatics Group, Oxford, UK) [16] and iCAN analysis platform for nanobodies (Southeast University, Nanjing, Jiangsu Province, China) [17].

\subsection{Nanobodies Production}

The vectors containing 11 selected $\mathrm{Nbs}(\mathrm{Nb} 1$ to $\mathrm{Nb} 11)$ were transformed in E. coli BL21 strain and grown in $2 \mathrm{~L}$ Terrific Broth medium each, at $37^{\circ} \mathrm{C}$ until OD600 of 0.6. The expression was induced with $1 \mathrm{mM}$ IPTG at $18{ }^{\circ} \mathrm{C}$ over-night. Cells were harvested at $8000 \times g$ for $15 \mathrm{~min}$ and solubilized in $30 \mathrm{~mL} \mathrm{Nb}$ buffer (20 mM Tris- $\mathrm{HCl}$ pH 7.5, $400 \mathrm{mM} \mathrm{KCl,} 20 \mathrm{mM}$ imidazole) prior to sonication and centrifugation at $25,000 \times g$ for $20 \mathrm{~min}$. $\mathrm{Nb}$ proteins were purified from the clarified supernatant by incubation with $1 \mathrm{~mL}$ $\mathrm{Ni}^{2+}$ beads (Ni Sepharose ${ }^{\mathrm{TM}} 6$ Fast Flow) (GE Healthcare, Life Sciences, Uppsala, Sweden) for $1 \mathrm{~h}$ at $4{ }^{\circ} \mathrm{C}$, followed by 3 washes in $\mathrm{Nb}$ buffer and elution in $15 \mathrm{~mL} \mathrm{Nb}$ buffer with $400 \mathrm{mM}$ imidazole added. Next, the eluted $\mathrm{Nbs}$ were concentrated to $10-15 \mathrm{mg} / \mathrm{mL}$ and run on a SEC column with SEC buffer (20 mM MOPS pH 6.8, $80 \mathrm{mM} \mathrm{KCl,20 \%} v / v$ glycerol, $3 \mathrm{mM} \mathrm{MgCl}_{2}, 0.015 \% w / v \mathrm{C}_{12} \mathrm{E}_{8}$ ) without reducing agent. The main peak was collected, concentrated to $5 \mathrm{mg} / \mathrm{mL}(370 \mu \mathrm{M})$, and stored at $-80^{\circ} \mathrm{C}$.

\subsection{Functional Assay}

\subsubsection{SEC Co-Elution}

Samples of SsZntA $(40 \mu \mathrm{M})$ were incubated with $\mathrm{Nb}$ from 1 to $11(40 \mu \mathrm{M})$ in $40 \mathrm{mM}$ MOPS pH 6.8, $80 \mathrm{mM} \mathrm{KCl}, 20 \% v / v$ glycerol, $1 \mathrm{mM} \mathrm{MgCl}$, $1 \mathrm{mM}$ TCEP (tris(2-carboxyethyl) phosphine) (Sigma-Aldrich), $0.15 \mathrm{mg} / \mathrm{mL} \mathrm{C}_{12} \mathrm{E}_{8}$ for $30 \mathrm{~min}$ at room temperature in a final volume of $50 \mu \mathrm{L}$ and run on analytic-scale SEC (column volume of $2.4 \mathrm{~mL}$, flow $0.04 \mathrm{~mL} / \mathrm{min}$ ) equilibrated with the same buffer, to separate SsZntA-Nb complex from unbound proteins. Then, fractions were run on a denaturing SDS-PAGE to visualize the presence of SsZntA and Nb. For the Nbs that showed complex formation, the assay was scaled-up to obtain more reproducible and stable signals: $40 \mu \mathrm{M}$ SsZntA was incubated with $100 \mu \mathrm{M} \mathrm{Nb}$ in $50 \mu \mathrm{L}$ and then diluted to $500 \mu \mathrm{L}$ prior to running in a medium-scale SEC (column volume of $24 \mathrm{~mL}$, flow $0.05 \mathrm{~mL} / \mathrm{min})$.

\subsubsection{Ni-NTA Co-Elution}

In this assay, $13 \mathrm{nmol}$ of SsZntA were incubated with $44 \mathrm{nmol}$ of one of Nb1-2-4-5-8-9 in 20 $\mathrm{mM}$ MOPS pH 7.5, $200 \mathrm{mM} \mathrm{KCl,} \mathrm{20 \%} v / v$ glycerol, $1 \mathrm{mM} \mathrm{MgCl}_{2}, 0.015 \% w / v \mathrm{C}_{12} \mathrm{E}_{8}, 5 \mathrm{mM} \mathrm{BME}$, for $1 \mathrm{~h}$ on ice in a final volume of $500 \mu \mathrm{L}$. The samples were then adjusted to $400 \mathrm{mM} \mathrm{KCl}$ and 50 $\mathrm{mM}$ imidazole, and run on a $1 \mathrm{~mL}$ HisTrap HP (GE Healthcare, Life Sciences, Uppsala, Sweden) equilibrated with the same buffer at $0.3 \mathrm{~mL} / \mathrm{min}$. Fractions were collected and run on a SDS-PAGE gel, then stained with InVision ${ }^{\mathrm{TM}}$ HisTag In-gel Stain (Thermo Fisher Scientific, Roskilde, Denmark), according to the manual, to assess the presence of HisTagged proteins followed by Coomassie-staining for total protein detection.

\subsubsection{ATPase Activity Assay}

The Baginski assay was used to measure ATPases activity and was conducted as previously described [3]. Briefly, 0.8 $\mu \mathrm{M}$ SsZntA was incubated with no Nb, $1.6 \mu \mathrm{M} \mathrm{Nb} 1$ to 9, $1.6 \mu \mathrm{M} \mathrm{AlF} 3,2 \mathrm{mM}$ $\mathrm{AlF}_{3}$, and $0.2,0.4,0.8,1.2,1.6,2,2.4,2.8,3.2,6.4 \mu \mathrm{M} \mathrm{Nb} 9$ in $40 \mathrm{mM}$ MOPS pH $6.8,150 \mathrm{mM} \mathrm{NaCl}$, $5 \mathrm{mM} \mathrm{MgCl}_{2}, 20 \mathrm{mM}\left(\mathrm{NH}_{4}\right)_{2} \mathrm{SO}_{4}$ (VWR), $20 \mathrm{mM}$ L-cysteine (VWR), $5 \mathrm{mM} \mathrm{NaN}_{3}$ (Sigma-Aldrich), $0.25 \mathrm{mM} \mathrm{Na}_{2} \mathrm{MoO}_{4}$ (Sigma-Aldrich), $1.2 \mathrm{mg} / \mathrm{mL}$ soybean lipids (Sigma-Aldrich), 0.3\% $w / v \mathrm{C}_{12} \mathrm{E}_{8}$, $0.5 \mathrm{mM} \mathrm{ZnSO}_{4}$ (Alfa Aesar by Thermo Fisher Scientific, Karlsruhe, Germany), in a total volume of $50 \mu \mathrm{L}$ for $1 \mathrm{~h}$ at room temperature and the assay was started by addition of $5 \mathrm{mM}$ ATP. The reaction 
was stopped after $15 \mathrm{~min}$ and after $30 \mathrm{~min}$ by adding $50 \mu \mathrm{L}$ Stop solution $(2.5 \% w / v$ ascorbic acid (Sigma-Aldrich), $0.4 \mathrm{M} \mathrm{HCl}, 0.48 \% w / v\left(\mathrm{NH}_{4}\right)_{6} \mathrm{Mo}_{7} \mathrm{O}_{24}$ (Fluka Analytical, Bucharest, Romania), $0.8 \% w / v$ SDS (Sigma-Aldrich)) and then $75 \mu \mathrm{L}$ of arsenic solution ( $2 \% w / v$ arsenite (Sigma-Aldrich, $2 \% v / v$ acetic acid (VWR), 3.5\% $w / v$ sodium citrate (VWR)), respectively. The absorbance was measured in a microplate reader at $860 \mathrm{~nm}$ and the signal normalized with a sample without protein as phosphate background. When testing $\mathrm{Nb} 9$ with LpCopA and MmCadA, the same conditions were applied, except the use of $\mathrm{CuSO}_{4}$ as a metal ion with LpCopA.

\section{Results}

\subsection{Isolation of Native SsZntA}

SsZntA was produced in E. coli C43 cells and initially purified by immobilized metal affinity chromatography (IMAC). The $8 \times$ histidine tag (HisTag) was removed using the TEVp cleavage site, which is important since the HisTag can bind zinc and other metals, potentially interfering with activity and binding assays. Detergent solubilized SsZntA was purified by HisTag-based affinity chromatography and treated with TEVp to remove the HisTag and subjected to affinity purification again, achieving complete separation of cleaved SsZntA, uncleaved (HisTagged) SsZntA, and HisTagged TEVp (Figure 2). The flow-through of the second affinity chromatography (R-IMAC) contained completely cleaved and pure SsZntA, while uncleaved SsZntA and TEVp were present in fractions containing $250 \mathrm{mM}$ and $500 \mathrm{mM}$ imidazole, respectively. SsZntA was further purified using size-exclusion chromatography (SEC), achieving a high degree of purity, as assessed by SDS-PAGE, and homogeneity, as assessed by SEC (Figure 3). The final yield of SsZntA is 5 to $10 \mathrm{mg}$ per liter of culture.

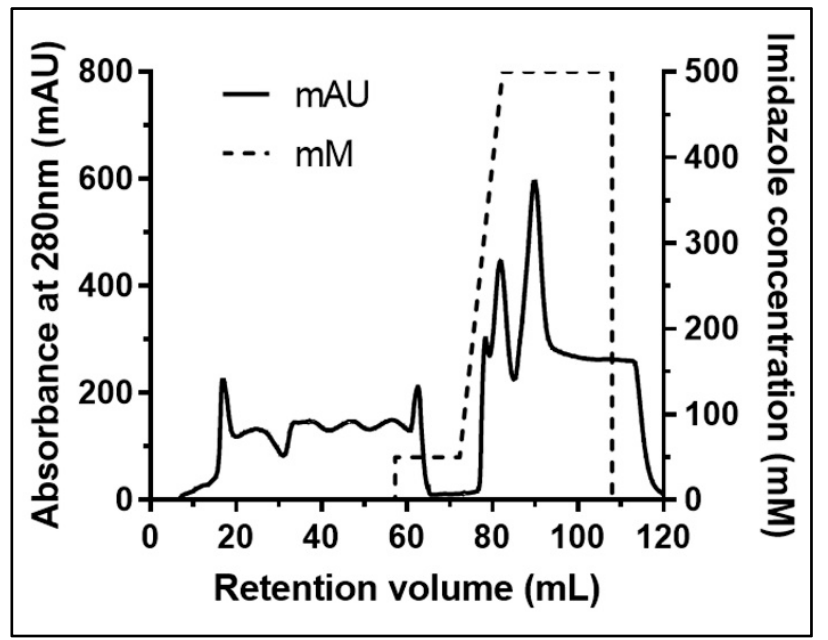

(a)

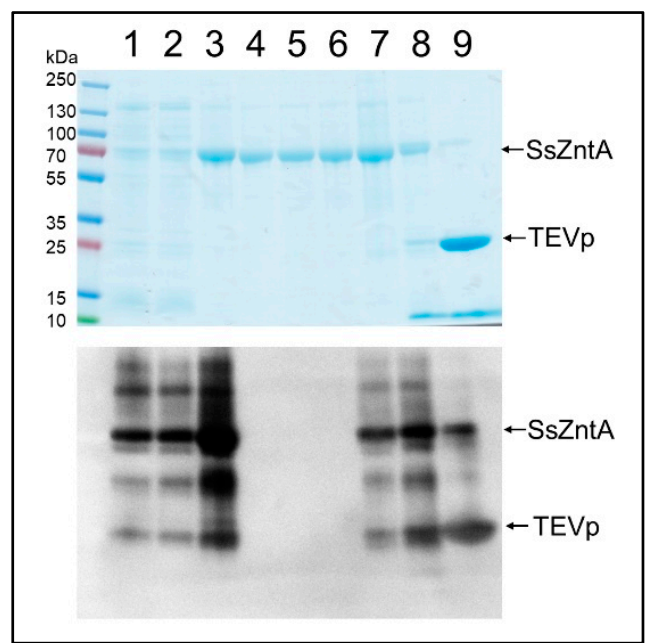

(b)

Figure 2. Purificaiton of the zinc-transporter SsZntA from Shigella sonnei: (Reverse-affinity chromatography) R-IMAC. (a) Reverse (second) affinity chromatography profile: The first $60 \mathrm{~mL}$ represent the flow-through containing cleaved SsZntA (without HisTag); at $80 \mathrm{~mL}$, corresponding to $250 \mathrm{mM}$ imidazole, uncleaved SsZntA is eluted; while at $90 \mathrm{~mL}$, at $500 \mathrm{mM}$ imidazole, HisTagged TEVp is eluted. (b) On top, Coomassie stained sodium dodecyl sulfate-polyacrylamide gel electrophoresis (SDS-PAGE), and on the bottom, Western blot anti-HisTag; lane 1: Solubilized membranes, lane 2: Clarified solubilized membranes, lane 3: Affinity-chromatography purified SsZntA (with HisTag), lanes 4 to 6: Flow through of reverse affinity chromatography (SsZntA without HisTag) corresponding to retention volume from $0 \mathrm{~mL}$ to $60 \mathrm{~mL}$, lanes 7 to 9: Eluted fractions corresponding to retention volume of 80,85 , and $90 \mathrm{~mL}$, respectively. 


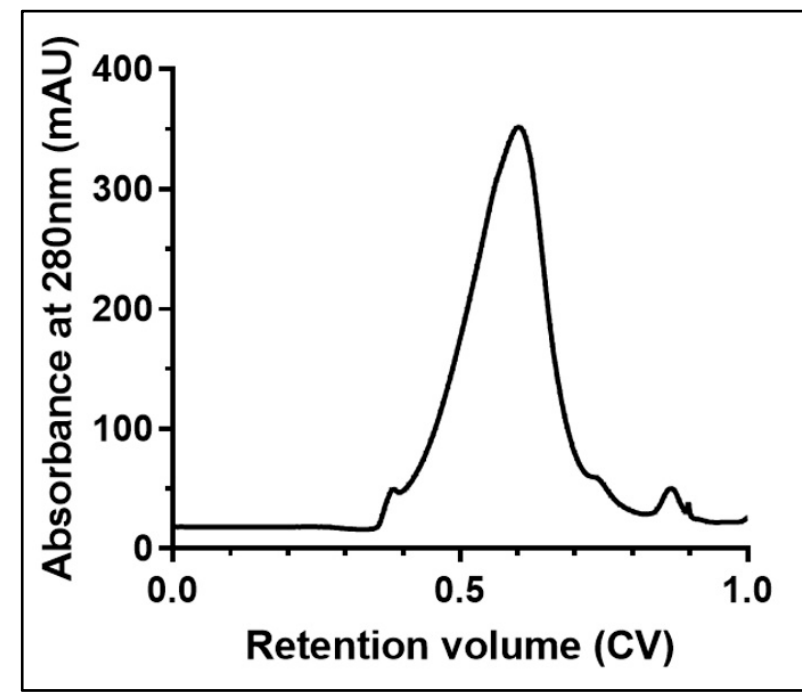

(a)

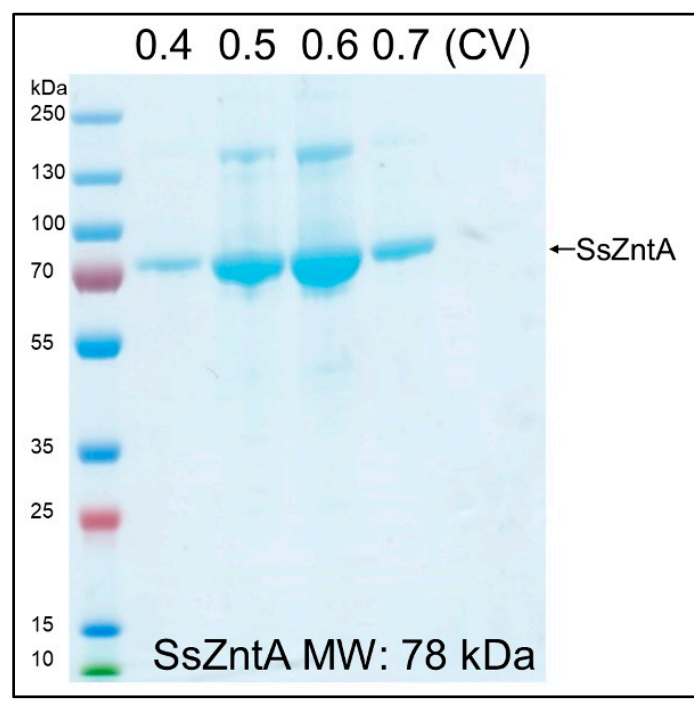

(b)

Figure 3. SsZntA purification: SEC. (a) Elution profile from a Superose6 size-exclusion column with a column volume $(\mathrm{CV})=24 \mathrm{~mL}$ : The main peak elutes at $0.6 \mathrm{CV}$, followed by minor contaminants. (b) Coomassie-stained SDS-PAGE containing the SEC fractions collected at 0.4, 0.5, 0.6, 0.7 CV; upper band at $150 \mathrm{kDa}$ is possibly SsZntA dimers (due to SDS artifacts).

\subsection{Isolation of Nanobodies}

The purified SsZntA sample (in $0.03 \%$ w $v$ DDM) was used for llama immunization with multiple injections during a period of 12 weeks. We generated an $\mathrm{Nb}$-library and, following two rounds of phage-display followed by enzyme-linked immunosorbent assay ELISA analysis, we found about 100 positive clones. These were reduced for highly redundant ones, resulting in 45 different $\mathrm{Nb}$ sequences that were grouped in three main families (Figure 4a). We decided to investigate $11 \mathrm{Nbs}$ covering most of the overall sequence variability: $\mathrm{Nb} 1, \mathrm{Nb} 2$, and $\mathrm{Nb} 3$ belong to the first family; $\mathrm{Nb} 4$ and $\mathrm{Nb} 5$ to the second family; $\mathrm{Nb6}$ and $\mathrm{Nb} 7$ to the third family; $\mathrm{Nb} 8, \mathrm{Nb} 9, \mathrm{Nb} 10$, and $\mathrm{Nb} 11$ did not fit in the previous families and are therefore considered outliers. Figure $4 \mathrm{~b}$ displays the primary structures of the selected $11 \mathrm{Nbs}$, where the portions corresponding to the three complementarity-determining regions (CDRs), as well as the predicted conserved secondary structure, are indicated. We then expressed and purified the selected $11 \mathrm{Nbs}$ (with HisTag) and tested them for SsZntA binding and inhibition. Expression in E. coli BL21 yielded 4-5 g wet cell weight, which resulted in 9-13 mg affinity-purified $\mathrm{Nb}$, per liter of culture. $\mathrm{Nb3}$ precipitated following affinity-chromatography and further work with it was, therefore, discontinued. The purified $\mathrm{Nb}$ s were subjected to SEC, achieving relatively pure $\mathrm{Nb}$ samples as analyzed using SDS-PAGE (Figure 5c). Purified SsZntA was tested with three different assays to assess binding (size-exclusion and nickel-affinity chromatography) and inhibitory (ATPase activity) properties of the purified $\mathrm{Nbs}$. 


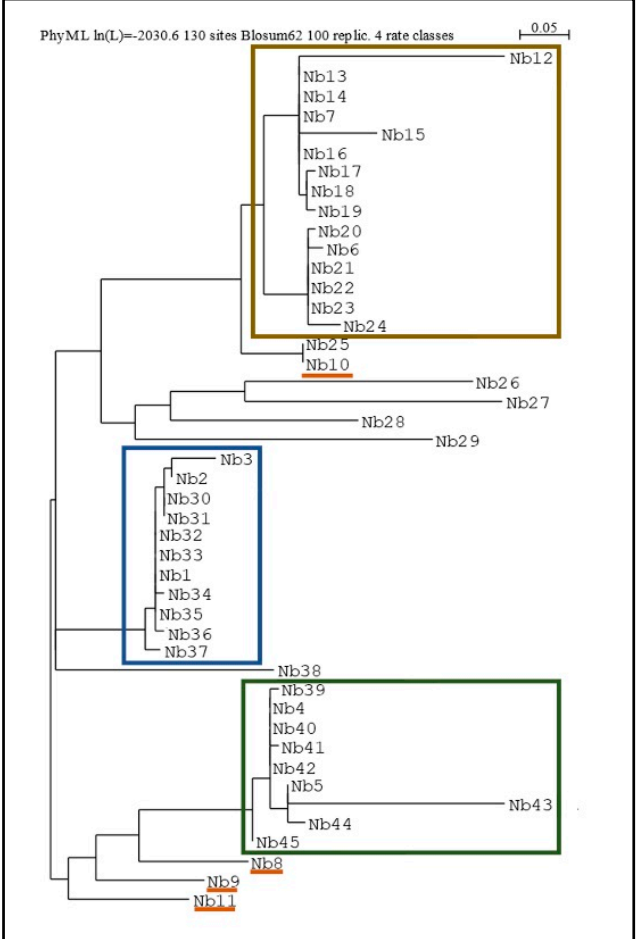

(a)

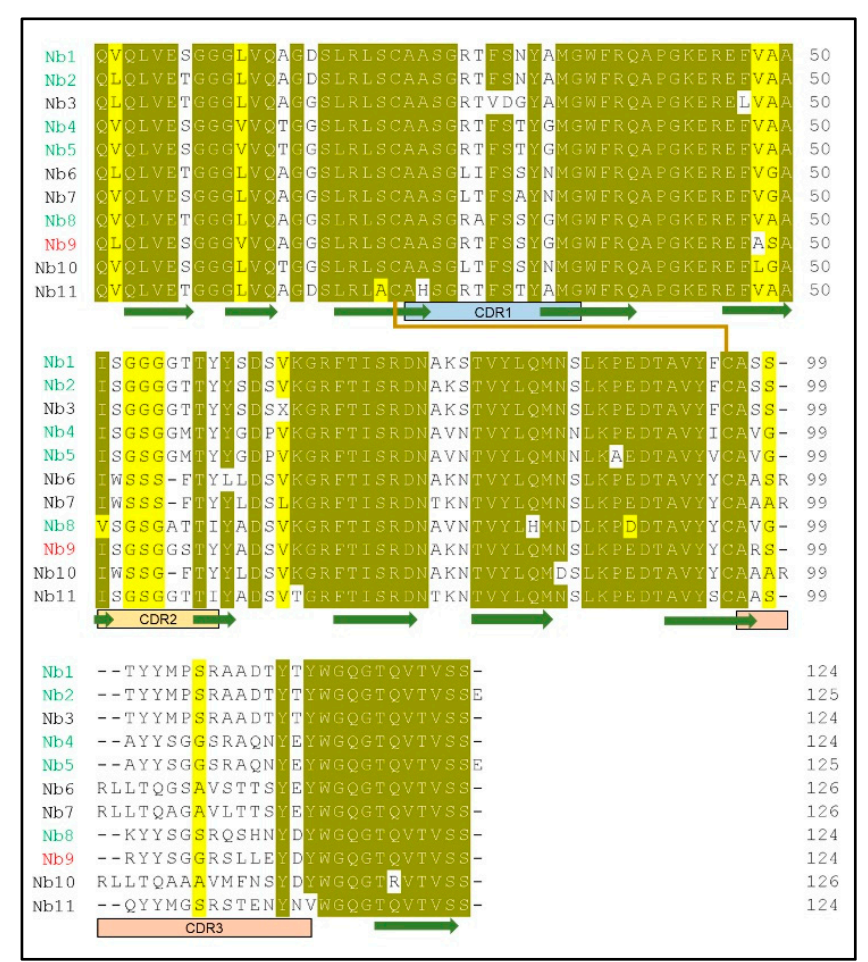

(b)

Figure 4. Sequence analysis of the identified Nbs. (a) Phylogenetic tree of $45 \mathrm{Nb}$ sequences: The three main families of $\mathrm{Nbs}$ are highlighted by colored boxes: The first family (blue box) includes Nb1-2-3, the second family (green) includes $\mathrm{Nb} 4-5$, the third family (ochre) is composed of two subfamilies, which include $\mathrm{Nb6}$ and $\mathrm{Nb} 7$, while Nb8-9-10-11 were sampled as outliers. (b) Sequence alignment of the 11 selected $\mathrm{Nbs}$ containing the predicted secondary structure ( $\beta$-sheets are shown as green arrows), the complementarity-determining regions (CDR1 to 3), and the conserved disulphide bond (orange line). Identical (90\% threshold) residues are in dark yellow while similar amino acids in light yellow. $\mathrm{Nbs}$ that bind to SsZntA, but do not inhibit activity, are represented with a green name (Nb1-2-4-5-8), while in red, the $\mathrm{Nb}$ that significantly inhibits ATPase activity ( $\mathrm{Nb} 9)$. The $\mathrm{Nbs}$ that precipitated during purification $(\mathrm{Nb3})$ or that caused precipitation of SsZntA (Nb6-7-10-11) are represented in black.

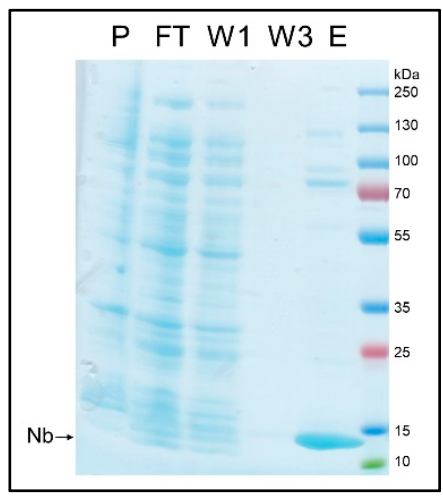

(a)

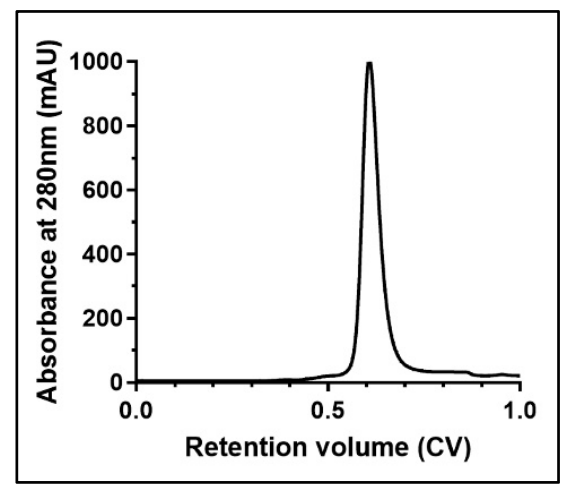

(b)

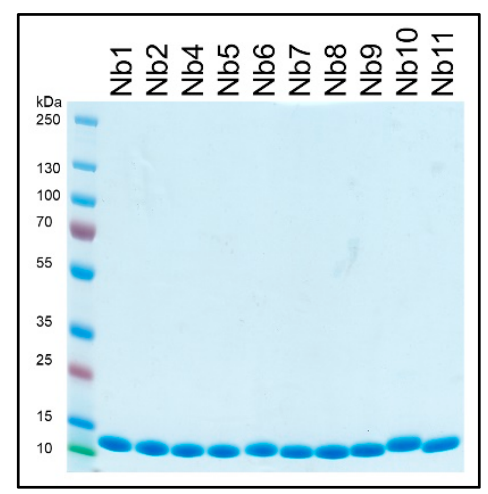

(c)

Figure 5. Nanobody purification. Samples from purification of $\mathrm{Nb} 1$ are representative of all the assessed Nbs. (a) Samples from insoluble fraction (pellet, P), flow-through of the IMAC (FT), first and third wash of $\mathrm{Ni}^{2+}$-beads (W1 and $\mathrm{W} 3$, respectively), and eluted fraction containing $\mathrm{Nb} 1$ loaded on Coomassie-stained SDS-PAGE. (b) SEC (24mL, Superose 75 ) elution profile: The main peak elutes at 0.6 $\mathrm{CV}$ with only minor contaminants. (c) Coomassie-stained SDS-PAGE of SEC-purified Nbs: Nbs have a molecular weight of approximately $13.5 \mathrm{kDa}$. 


\subsection{Size-Exclusion Chromatography (SEC) Co-Elution}

Nbs were incubated with SsZntA and subjected to SEC to assess complex formation. We tested the binding in a small-scale size-exclusion column $(2.4 \mathrm{~mL})$ and in a medium-scale column $(24 \mathrm{~mL})$. The latter was used only on Nbs, which proved to bind to SsZntA in order to obtain a more stable signal and improve the signal-to-noise ratio. The chromatogram reported in Figure $6 \mathrm{a}$ is acquired from the medium scale column obtained from $\mathrm{Nb} 1$ and is representative of those obtained from $\mathrm{Nb2}-4-5-8-9$ (results not shown), and shows the first peak at 0.6 CV $(14.5 \mathrm{~mL})$ containing the SsZntA-Nb complex and the second peak at $0.85 \mathrm{CV}(20.5 \mathrm{~mL})$ containing unbound $\mathrm{Nb}$. The overlaying dashed and dotted lines represent the chromatograms obtained from $\mathrm{Nb} 1$ and SsZntA, respectively, under the same conditions. As summarized in Table 1, six Nbs (Nb1-2-4-5-8-9) displayed co-elution, suggesting SsZntA-Nb interaction. Nb6-7-10-11 caused precipitation of SsZntA and hence these Nbs were not tested in subsequent assays.

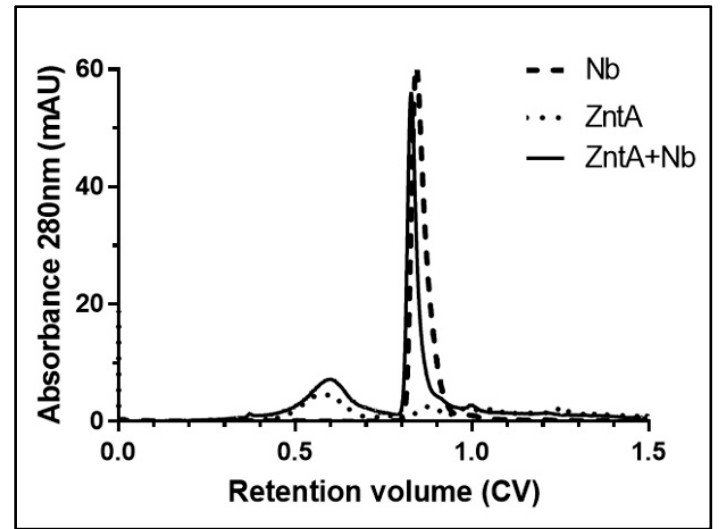

(a)

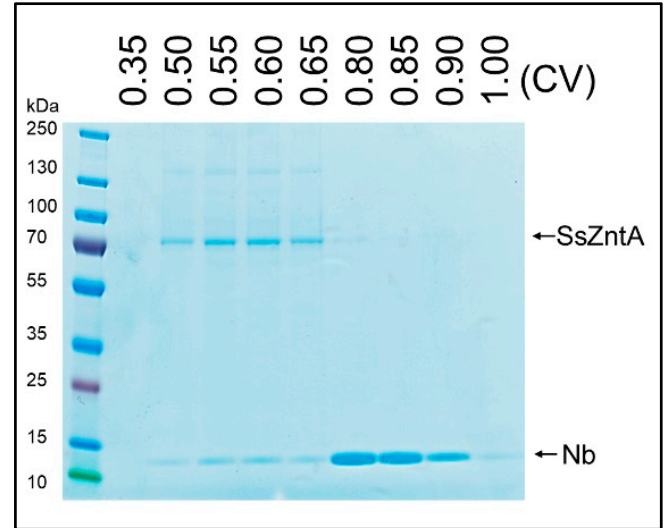

(b)

Figure 6. SsZntA-Nb complex analysis using size-exclusion chromatography. (a) Black line: Chromatogram of SsZntA $(40 \mu \mathrm{M})$ incubated with $\mathrm{Nb} 1(100 \mu \mathrm{M})$ in a final volume of $50 \mu \mathrm{L}$ (then diluted to $500 \mu \mathrm{M}$ ) and run through a size-exclusion column (Superose6, $1 \mathrm{CV}=24 \mathrm{~mL}$ ) showing a peak at $0.6 \mathrm{CV}$, which contains the SsZntA-Nb complex, and a peak at $0.85 \mathrm{CV}$, which contains unbound $\mathrm{Nb}$. The dashed line represents the chromatogram of $\mathrm{Nb} 1$ alone, while the dotted line the one from SsZntA alone (under the same condition). (b) Coomassie-stained SDS-PAGE gel of the fractions collected at $0.35,0.5,0.55,0.6,0.65,0.8,0.85,0.9,1 \mathrm{CV}$.

Table 1. Size-exclusion chromatography co-elution results.

\begin{tabular}{ccc}
\hline Tested Nb & Binding & Precipitation \\
\hline $\mathrm{Nb} 1$ & + & - \\
$\mathrm{Nb} 2$ & + & - \\
$\mathrm{Nb} 4$ & + & - \\
$\mathrm{Nb} 5$ & + & - \\
$\mathrm{Nb} 6$ & $\mathrm{~N} . \mathrm{D}$. & + \\
$\mathrm{Nb} 7$ & $\mathrm{~N} . \mathrm{D}$ & + \\
$\mathrm{Nb} 8$ & + & - \\
$\mathrm{Nb} 9$ & + & - \\
$\mathrm{Nb} 10$ & $\mathrm{~N} . \mathrm{D}$. & + \\
$\mathrm{Nb} 11$ & N.D. & + \\
\hline
\end{tabular}

Not determined (N.D.): Due to sample precipitation, binding could not be assessed.

\subsection{Affinity Purification Co-Elution}

The engineered HisTag of the Nbs was used to assess binding, as illustrated in Figure 7. Nb1-2-4-5-8-9 were incubated with HisTag-free SsZntA and subjected to HisTag-based affinity chromatography. The samples were then subjected to SDS-PAGE and stained with InVision ${ }^{\circledR}$ HisTag 
In-gel staining to evaluate the presence of the HisTag in the protein bands. The results in Figure 8 represent control experiments. Panel (a) confirms that the HisTag-free SsZntA appears in the flow-through and is therefore lacking $\mathrm{Ni}^{2+}$-binding capacity; panel (b) shows that HisTagged SsZntA $\left(\right.$ lane + ) is stained by the InVision ${ }^{\circledR}$ dye, resulting in a clear band. Figure 9a reveals that binding of $\mathrm{Nb1}$ to SsZntA allows for retention of the latter in the $\mathrm{Ni}^{2+}$-immobilized resin, proving that an $\mathrm{Nb}-\mathrm{SsZntA}$ complex forms; $\mathrm{Nb} 2-4-5-8-9$ behaved similarly to $\mathrm{Nb} 1$ (results not shown). In Figure $9 \mathrm{~b}$, it is verified that the bands corresponding to SsZntA do not present a HisTag, while the Nbs do.

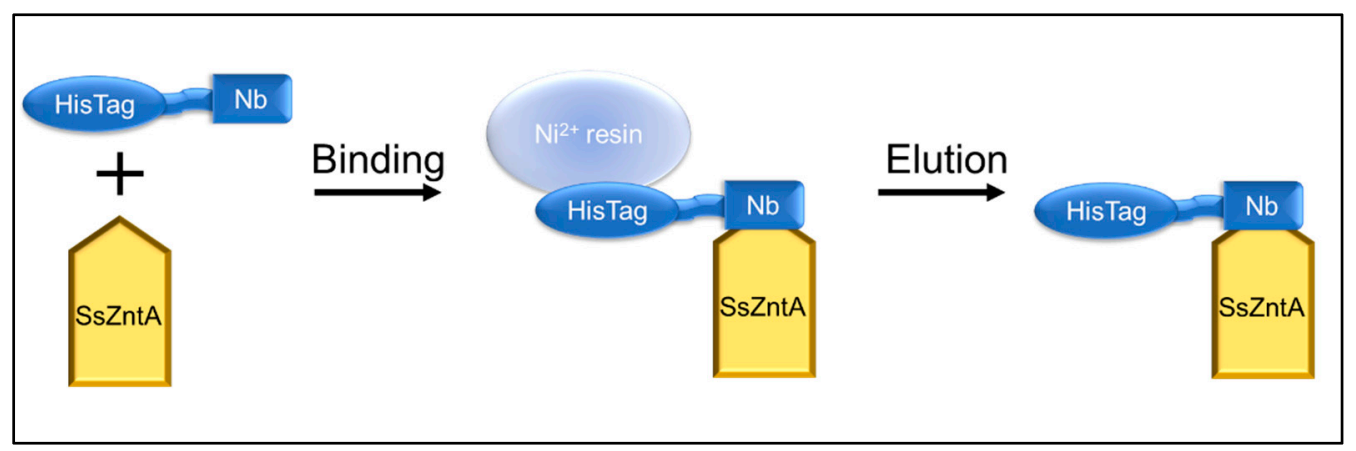

Figure 7. Affinity chromatography binding assay. SsZntA is treated with TEVp to remove the HisTag, in this way it cannot bind to a $\mathrm{Ni}^{2+}$ beads, while the HisTagged nanobody can. The binding was assessed by incubating HisTag-free SsZntA with HisTagged $\mathrm{Nb}$ and loading them to an Ni-NTA column. When SsZntA forms a complex with the $\mathrm{Nb}$, it indirectly binds to the $\mathrm{Ni}^{2+}$ beads (via the $\mathrm{Nb}^{\prime} \mathrm{s}$ HisTag) and can be eluted from the $\mathrm{Ni}^{2+}$-immobilized resin. N.B. All the representations are out of scale for clarity.

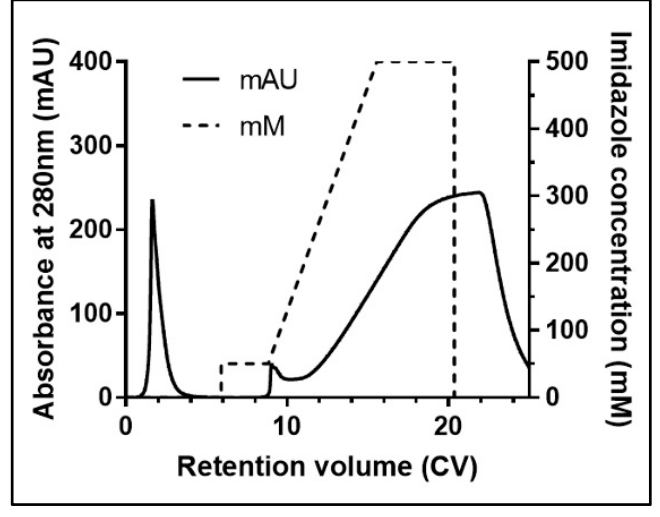

(a)

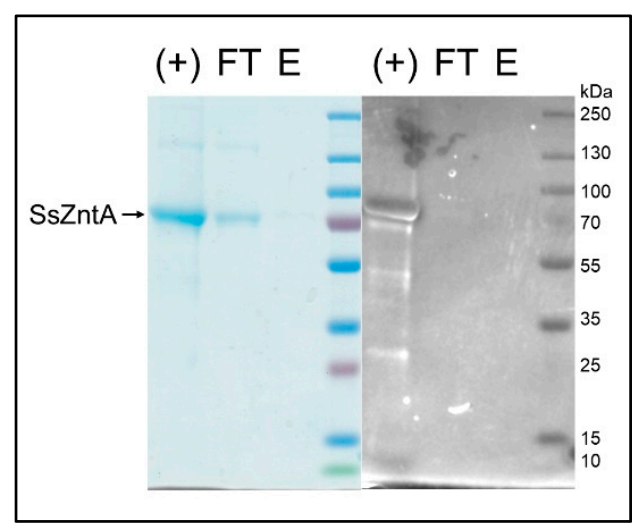

(b)

Figure 8. SsZntA-Nb complex analysis using affinity chromatography: SsZntA only. (a) Chromatogram of HisTag-free SsZntA loaded on an $\mathrm{Ni}^{2+}$-immobilized column. Without $\mathrm{Nb}$, the ATPase elutes in the flow through (control). (b) Coomassie (left) and InVision ${ }^{\circledR}$ (right) stained SDS-PAGE of HisTagged SsZntA as positive control for the staining (+), flow through (FT), and eluted fraction (E) of HisTag free SsZntA loaded on the $\mathrm{Ni}^{2+}$-immobilized resin as negative control. 


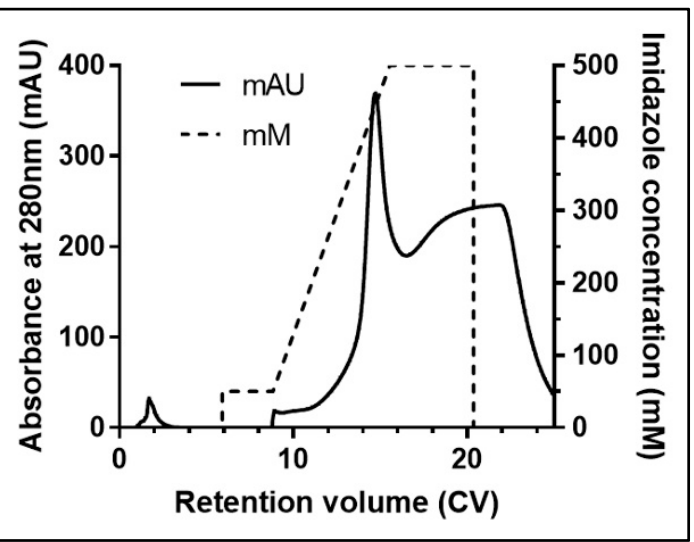

(a)

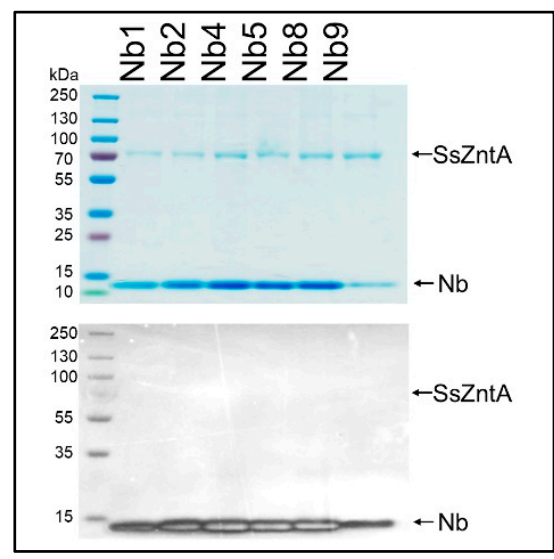

(b)

Figure 9. SsZntA-Nb complex analysis using affinity chromatography: SsZntA + Nb. (a) Chromatogram of HisTag-free SsZntA incubated with HisTagged Nb1. The complex elutes at $400 \mathrm{mM}$ imidazole and is here reported as representative of the other Nbs. (b) Coomassie (top) and InVision ${ }^{\circledR}$ (bottom) stained SDS-PAGE of the eluted fractions at $400 \mathrm{mM}$ imidazole of HisTag-free SsZntA in complex with, respectively, Nb1-2-4-5-8-9.

\section{5. $\mathrm{Nb}$ Effect on SsZntA Functionality}

We used the Baginski assay to access $\mathrm{Nb}$-induced inhibition of SsZntA, which estimates the amount of released inorganic phosphate $\left(\mathrm{P}_{\mathrm{i}}\right)$ associated with the catalytical cycle (ATP turn-over, 1 mole $P_{i}$ equals 1 mole of transported zinc). Different batches of $\mathrm{Nbs}$ were tested for inhibitory activity at a molar ratio of 1 (SsZntA) to $2(\mathrm{Nb})$, corresponding to $8 \mu \mathrm{M}$ SsZntA and $16 \mu \mathrm{M} \mathrm{Nbs,}$ yielding the results shown in Figure 10a: Wild-type SsZntA without added $\mathrm{Nb}$ displays a specific activity of $885 \pm 87 \mathrm{nmol} \mathrm{P}_{\mathrm{i}} \mathrm{mg}^{-1} \mathrm{~min}^{-1}$, which is comparable to the activity previously reported [18]. $\mathrm{Nb} 9$ reduces the ATPase activity to around $50 \%$ of wild-type, showing a significant inhibition with a $p$ value $<0.0001$ (Dunn's multiple comparison test). The inhibition on the ATPase activity by the other $\mathrm{Nbs}$ is non-significant at the concentrations tested. We included the phosphate analog, aluminum fluoride $\left(\mathrm{AlF}_{3}\right)$, as a control of the ATPase inhibition assay at two different concentrations: $1.6 \mu \mathrm{M}$ (as the $\mathrm{Nbs}$ ) and $2 \mathrm{mM}$ (previously reported [3] working concentration). $\mathrm{AlF}_{3}$ does not affect ATPase activity at $1.6 \mu \mathrm{M}$, showing that the affinity for $\mathrm{SsZntA}$ of $\mathrm{Nb} 9$ is higher than that of $\mathrm{AlF}_{3}$. In Figure $10 \mathrm{~b}$, a titration experiment of $\mathrm{Nb} 9$ with different molar ratios is reported: $\mathrm{Nb} 9$ inhibits ATPase activity of SsZntA when present at least at a molar ratio 1:1 (SsZntA:Nb9) and has the maximum inhibitory effect (at about 50\%) at the molar ratio of 1:3 (SsZntA:Nb9). To assess Nb9 specificity, it was further tested against CopA from Legionella pneumophila (LpCopA): A member of the same subfamily as SsZntA ( $\mathrm{P}_{\text {IB }}$-type, 34\% identity to SsZntA), but transporting $\mathrm{Cu}^{+}$instead of $\mathrm{Zn}^{2+}$, and against $\mathrm{CadA}$ from Mesorhizobium metallidurans (MmCadA); $\mathrm{Cd}^{2+}$ and $\mathrm{Zn}^{2+}$-transporting ATPase from the same subclass as SsZntA (P $\mathrm{P}_{\mathrm{IB}-2}$-type, 53\% identity). LpCopA and MmCadA were purified similarly to SsZntA and yield highly pure protein (Figure 11a). As shown in Figure 11b, Nb9 did not inhibit ATPase activity for any of the two proteins, suggesting that $\mathrm{Nb9}$ is specific for SsZntA. 


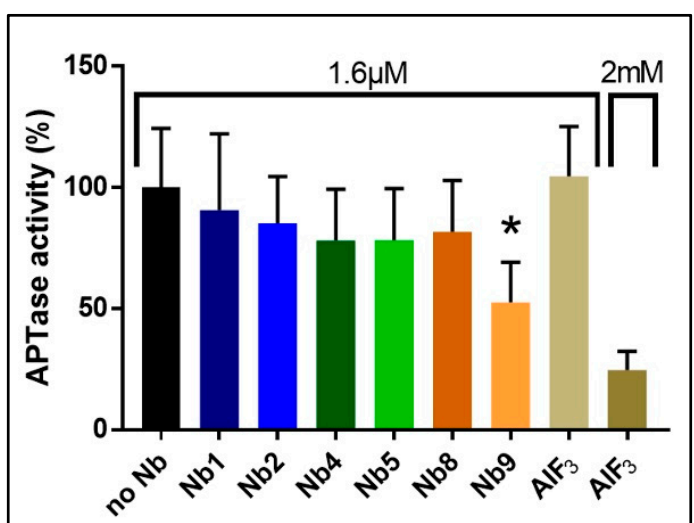

(a)

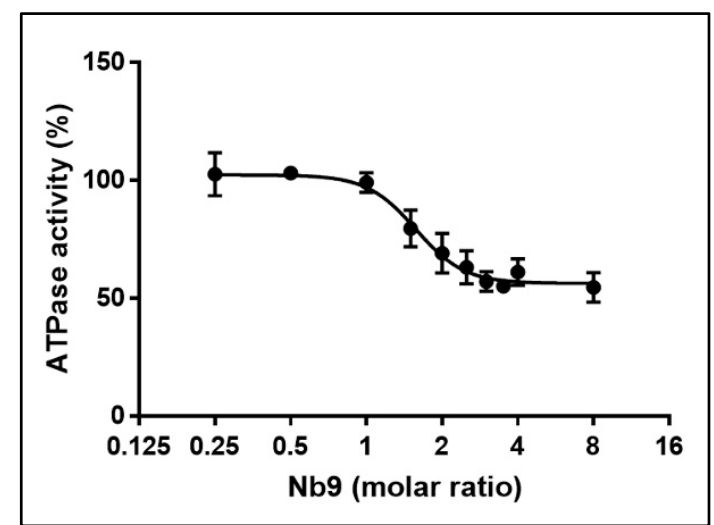

(b)

Figure 10. Nanobody effect on the catalytical function. (a) SsZntA was incubated with each $\mathrm{Nb}$ at a 1:2 molar ratio (i.e., $1.6 \mu \mathrm{M}$ ) and activity was assessed. $\mathrm{Nb} 9$ displayed an inhibitory effect of about $50 \%$ compared to untreated (no $\mathrm{Nb}$ ) SsZntA. The difference between no $\mathrm{Nb}$ and $\mathrm{Nb} 9$ has a $p$ value of $\left.<0.0001{ }^{*}\right)$, as assessed by a Dunn's multiple comparison test. The ATPase inhibitor aluminum fluoride $\left(\mathrm{AlF}_{3}\right)$ is shown as a positive control, at $1.6 \mu \mathrm{M}$ (corresponding to the concentration of the tested $\mathrm{Nbs}$ ) and at $2 \mathrm{mM}$. (b) The inhibition stoichiometry was assessed as titration of SsZntA with different molar ratios of $\mathrm{Nb} 9$. The inhibitory effect appears when $\mathrm{Nb} 9$ is present at a molar ratio of 1:1 (ZntA: $\mathrm{Nb} 9$ ), and reaches the inhibitory plateau at a molar ratio of $1: 3(\mathrm{ZntA}: \mathrm{Nb} 9)$, with an $\mathrm{IC}_{50}=1.57$ molar ratio.

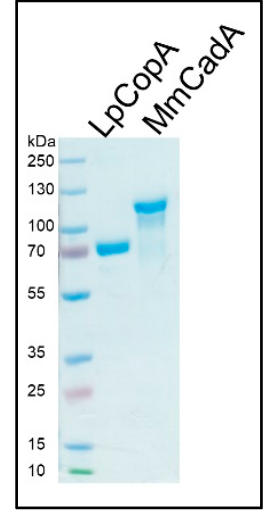

(a)

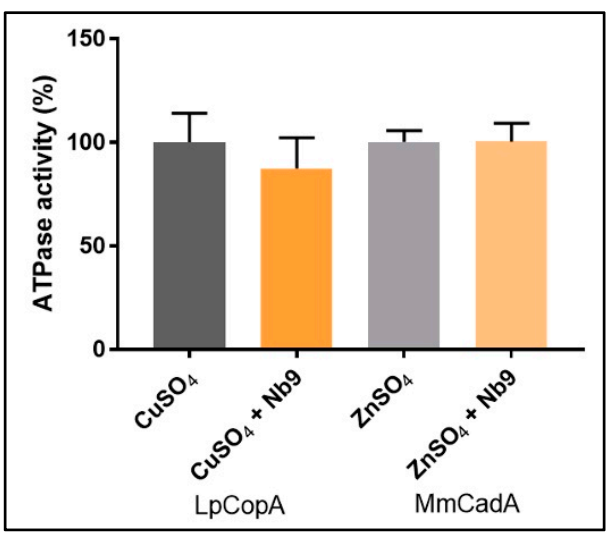

(b)

Figure 11. $\mathrm{Nb} 9$ specificity. (a) SDS-PAGE of purified $\mathrm{Cu}^{+}$-transporting $\mathrm{P}_{\mathrm{IB}-1}$-ATPase from Legionella pneumophila (LpCopA) and $\mathrm{Cd}^{2+}$ and $\mathrm{Zn}^{2+}$-transporting $\mathrm{P}_{\mathrm{IB}-2}$-ATPase from Mesorhizobium metallidurans (MmCadA) (b) $\mathrm{Nb9}$ was tested for specificity against LpCopA and against MmCadA, in the presence of $\mathrm{Cu}^{+}$or $\mathrm{Zn}^{2+}$, respectively. The results are normalized for the background in presence of the metal ion chelator EDTA.

\section{Discussion}

P-type ATPases are characterized by a transmembrane domain, embedding the ion binding site(s), and a large soluble portion, which includes catalytic and regulatory domains. Each domain has a particular function that requires an overall maintained structural integrity: The relative arrangements of these domains, and their ability to undergo conformational changes, is of crucial importance for the ATPase function and the ion translocation activity [19]. Hence, ATP and phosphate analogs (e.g., AMPPCP (Adenylylmethylenediphosphonate disodium salt) [20] or $\mathrm{AlF}_{3}$ [21]) that occupy the nucleotide binding or phosphorylation site in the soluble portion, preventing hydrolysis, inhibit also translocation of transported ion(s) through the transmembrane domain. In this study, $\mathrm{Nbs}$ were selected as tool compounds, exploiting their ability to bind to cavities and active sites of proteins due to a combination of the small size and convex paratope [22]. We identified Nbs that bind specifically to 
the model zinc-transporting $\mathrm{P}_{\mathrm{IB}}$-type ATPase SsZntA to widen the toolset available for structural and functional studies of this subclass of ATPases.

Isolated membranes containing SsZntA were solubilized in DDM, followed by detergent exchange to $\mathrm{C}_{12} \mathrm{E}_{8}$ using affinity chromatography. For the samples exploited for immunization, but not those used for selection, an additional detergent exchange to DDM was performed during SEC. DDM is frequently the detergent of choice for membrane proteins, providing efficient solubilization, stabilization, and preventing non-specific interaction for many membrane protein targets. This means that DDM is suitable if the aim is to reduce interaction and aggregation with other soluble and membrane proteins, as in the case of llama immunization. The SsZntA samples used for $\mathrm{Nb}$ selection were instead purified in $0.015 \% w / v \mathrm{C}_{12} \mathrm{E}_{8}$ : This detergent provides a smaller micelle size and, therefore, leaves more of the protein exposed for interactions. Detergents that give a small micelle size are preferred for structural biology studies, increasing the possibility for protein-protein interactions, which are essential for crystal-lattice formation [23]. In this work, the final aim was to provide new tools for SsZntA crystallization, and thus the identified Nbs need to bind and/or inhibit in the presence of the detergent used for crystallization studies of many P-type ATPases: $C_{12} E_{8}[3,24-26]$. Therefore, the selection was performed using $\mathrm{C}_{12} \mathrm{E}_{8}$ solubilized SsZntA, but we anticipate similar results in the presence of other mild detergents, including DDM.

Following screening of the initial $\mathrm{Nb}$ hits, we selected 11 for further studies, attempting to address variability in the sequences. As shown in Figure $4(\mathbf{b})$, the selected $\mathrm{Nbs}$ display distinct differences in the complementarity determining regions (CDR), while the conserved motifs and predicted scaffold structure are maintained. This observation is in line with previous findings on $\mathrm{Nbs}$, since the CDRs are constituted by residues responsible for antigen binding, and different residue combinations potentially bind to different antigens. Among the selected $11 \mathrm{Nbs}$, one (Nb3) could not be purified and four ( $\mathrm{Nb} 6$, $\mathrm{Nb} 7, \mathrm{Nb} 10, \mathrm{Nb} 11$ ) caused precipitation of the sample when mixed with SsZntA, and could thus not be tested in further assays. We believe that the observed precipitation can relate to the presence of detergent, perhaps in combination with $\mathrm{Nb}$ binding, which apparently compromises SsZntA further in this environment (e.g., through interaction with unstable intermediates or at sensitive regions of the proteins, such as the membrane interface). We successfully identified six $\mathrm{Nbs}(\mathrm{Nb} 1, \mathrm{Nb} 2, \mathrm{Nb} 4$, $\mathrm{Nb5}, \mathrm{Nb} 8, \mathrm{Nb} 9)$ which bind to SsZntA, while only one ( $\mathrm{Nb} 9)$ displays significant $(<50 \%)$ inhibition of the ATPase activity. $\mathrm{Nb} 9$ was tested against two other members of the heavy metal-transporting subfamily in order to assess its specificity: It does not inhibit the ATPase activity of neither a coppernor a zinc-transporting ATPase, denoting a high degree of specificity and a tight interaction with specific residues and/or conformations of SsZntA, which make it an ideal tool for studying in detail the transport cycle of this protein.

Further studies are needed to assess whether $\mathrm{Nb} 9$ inhibits the activity by binding between domains (as allosteric inhibitors), or if it occupies the ATP or the metal binding site, thus inhibiting the activity as competitive ligands, and if it blocks the reaction cycle by binding to a specific reaction cycle state. The latter is of particular interest, since it could be the first E1-specific inhibitor to be found for a metal-transporting P-type ATPase and would thus have extensive applications in both structural and functional characterization efforts. The fact that five out of six Nbs bind, but do not inhibit, the activity may hint that these Nbs associate to, for example, the more exposed portions of the soluble domains, and not to domain-domain interfaces. In any case, they can still be exploited as tools for structural biology studies: Co-crystallization of the Nbs with SsZntA is likely to alter crystal contacts/crystal packing by, for instance, generating a wider hydrophilic surface for lattice contacts. If stronger crystal contacts are obtained, it may result in an increased resolution of the diffraction data generated from these crystals. Moreover, the identified Nbs may serve as chaperones for cryo-EM experiments, with the aim of facilitating images' orientation, domain identification, and to render particles larger. In conclusion, this work provides the foundation for further usage of $\mathrm{Nbs}$ in structural studies of $\mathrm{P}_{\mathrm{IB}}$-type ATPases, aiming at expanding the available toolbox to achieve a greater understanding of this important, yet elusive, subfamily of enzymes. 
Author Contributions: Conceptualization, K.R.A., N.S.L. and P.G.; Formal analysis, E.L., C.G. and Q.H.; Funding acquisition, P.G.; Investigation, E.L., C.G., Q.H. and A.S.D.; Methodology, K.R.A.; Project administration, P.G.; Resources, K.R.A., N.S.L. and P.G.; Supervision, C.G., K.R.A., N.S.L. and P.G.; Validation, E.L., C.G., Q.H. and A.S.D.; Visualization, E.L.; Writing-original draft, E.L.; Writing一review \& editing, E.L., C.G., K.R.A., N.S.L. and P.G.

Funding: E.L. was funded by Lundbeck Foundation grant number R218-2016-1548. P.G. is supported by the following Foundations: Lundbeck, Knut and Alice Wallenberg, Carlsberg, Novo-Nordisk, Brødrene Hartmann, Agnes og Poul Friis, Augustinus, Crafoord as well as The Per-Eric and Ulla Schyberg. Funding is also obtained from The Independent Research Fund Denmark, the Swedish Research Council and through a Michaelsen scholarship. N.S.L. was funded by The Lundbeck Foundation.

Conflicts of Interest: The authors declare no conflict of interest.

\section{References}

1. Bublitz, M.; Morth, J.P.; Nissen, P. P-type ATPases at a glance. J. Cell Sci. 2011, 124, 2515-2519. [CrossRef] [PubMed]

2. Axelsen, K.B.; Palmgren, M.G. Evolution of substrate specificities in the P-type ATPase superfamily. J. Mol. Evol. 1998, 46, 84-101. [CrossRef] [PubMed]

3. Wang, K.; Sitsel, O.; Meloni, G.; Autzen, H.E.; Andersson, M.; Klymchuk, T.; Nielsen, A.M.; Rees, D.C.; Nissen, P.; Gourdon, P. Structure and mechanism of Zn2+-transporting P-type ATPases. Nature 2014, 514, 518. [CrossRef] [PubMed]

4. Kühlbrandt, W. Biology, structure and mechanism of P-type ATPases. Nat. Rev. Mol. Cell. Biol. 2004, 5, 282. [CrossRef] [PubMed]

5. Sitsel, O.; Duelli, A.; Gourdon, P. Zinc-Transporting P-Type ATPases. In Encyclopedia of Inorganic and Bioinorganic Chemistry; Scott, R.A., Ed.; John Wiley \& Sons, Ltd.: Hoboken, NJ, USA, 2016.

6. Post, R.L.; Sen, A.K.; Rosenthal, A.S. A phosphorylated intermediate in adenosine triphosphate-dependent sodium and potassium transport across kidney membranes. J. Biol. Chem. 1965, 240, 1437-1445. [PubMed]

7. Albers, R.W. Biochemical Aspects of Active Transport. Annu. Rev. Biochem. 1967, 36, 727-756. [CrossRef] [PubMed]

8. Apell, H.J. How do P-type ATPases transport ions? Bioelectrochemistry 2004, 63, 149-156. [CrossRef] [PubMed]

9. De Meyer, T.; Muyldermans, S.; Depicker, A. Nanobody-based products as research and diagnostic tools. Trends Biotechnol. 2014, 32, 263-270. [CrossRef] [PubMed]

10. Hamers-Casterman, C.; Atarhouch, T.; Muyldermans, S.; Robinson, G.; Hamers, C.; Songa, E.B.; Bendahman, N.; Hamers, R. Naturally occurring antibodies devoid of light chains. Nature 1993, 363, 446-448. [CrossRef] [PubMed]

11. Arbabi Ghahroudi, M.; Desmyter, A.; Wyns, L.; Hamers, R.; Muyldermans, S. Selection and identification of single domain antibody fragments from camel heavy-chain antibodies. FEBS Lett. 1997, 414, 521-526. [CrossRef]

12. Schmidt, T.G.M.; Skerra, A. The Strep-tag system for one-step purification and high-affinity detection or capturing of proteins. Nat. Protoc. 2007, 2, 1528. [CrossRef] [PubMed]

13. Hansen, S.B.; Laursen, N.S.; Andersen, G.R.; Andersen, K.R. Introducing site-specific cysteines into nanobodies for mercury labelling allows de novo phasing of their crystal structures. Acta Crystallogr. D Struct. Biol. 2017, 73, 804-813. [CrossRef] [PubMed]

14. Gouy, M.; Guindon, S.; Gascuel, O. SeaView Version 4: A Multiplatform Graphical User Interface for Sequence Alignment and Phylogenetic Tree Building. Mol. Biol. Evol. 2010, 27, 221-224. [CrossRef] [PubMed]

15. Stothard, P. The Sequence Manipulation Suite: JavaScript Programs for Analyzing and Formatting Protein and DNA Sequences. BioTechniques 2000, 28, 1102-1104. [CrossRef] [PubMed]

16. Leem, J.; Dunbar, J.; Georges, G.; Shi, J.; Deane, C.M. ABodyBuilder: Automated antibody structure prediction with data-driven accuracy estimation. $m A$ s 2016, 8, 1259-1268. [CrossRef] [PubMed]

17. Zuo, J.; Li, J.; Zhang, R.; Xu, L.; Chen, H.; Jia, X.; Su, Z.; Zhao, L.; Huang, X.; Xie, W. Institute collection and analysis of Nanobodies (iCAN): A comprehensive database and analysis platform for nanobodies. BMC Genomics 2017, 18, 797. [CrossRef] [PubMed]

18. Sharma, R.; Rensing, C.; Rosen, B.P.; Mitra, B. The ATP Hydrolytic Activity of Purified ZntA, a Pb(II)/Cd(II)/ Zn(II)-translocating ATPase from Escherichia coli. J. Biol. Chem. 2000, 275, 3873-3878. [CrossRef] [PubMed] 
19. Meng, D.; Bruschweiler-Li, L.; Zhang, F.; Brüschweiler, R. Modulation and Functional Role of the Orientations of the N- and P-Domains of Cu+-Transporting ATPase along the Ion Transport Cycle. Biochemistry 2015, 54, 5095-5102. [CrossRef] [PubMed]

20. Krasteva, M.; Barth, A. Structures of the Ca2+-ATPase complexes with ATP, AMPPCP and AMPPNP. An FTIR study. Biochim. Biophys. Acta. 2007, 1767, 114-123. [CrossRef] [PubMed]

21. Cho, H.; Wang, W.; Kim, R.; Yokota, H.; Damo, S.; Kim, S.-H.; Wemmer, D.; Kustu, S.; Yan, D. BeF3- acts as a phosphate analog in proteins phosphorylated on aspartate: Structure of a BeF3-complex with phosphoserine phosphatase. Proc. Nati. Acad. Sci. USA 2001, 98, 8525-8530. [CrossRef] [PubMed]

22. Beghein, E.; Gettemans, J. Nanobody Technology: A Versatile Toolkit for Microscopic Imaging, Protein-Protein Interaction Analysis, and Protein Function Exploration. Front. Immunol. 2017, 8. [CrossRef] [PubMed]

23. Gutmann, D.A.P.; Mizohata, E.; Newstead, S.; Ferrandon, S.; Henderson, P.J.F.; van Veen, H.W.; Byrne, B. A high-throughput method for membrane protein solubility screening: The ultracentrifugation dispersity sedimentation assay. Protein Sci. 2007, 16, 1422-1428. [CrossRef] [PubMed]

24. Andersson, M.; Mattle, D.; Sitsel, O.; Klymchuk, T.; Nielsen, A.M.; Møller, L.B.; White, S.H.; Nissen, P.; Gourdon, P. Copper-transporting P-type ATPases use a unique ion-release pathway. Nat. Struct. Mol. Biol. 2014, 21, 43-48. [CrossRef] [PubMed]

25. Olesen, C.; Picard, M.; Winther, A.-M.L.; Gyrup, C.; Morth, J.P.; Oxvig, C.; Møller, J.V.; Nissen, P. The structural basis of calcium transport by the calcium pump. Nature 2007, 450, 1036. [CrossRef] [PubMed]

26. Morth, J.P.; Pedersen, B.P.; Toustrup-Jensen, M.S.; Sørensen, T.L.M.; Petersen, J.; Andersen, J.P.; Vilsen, B.; Nissen, P. Crystal structure of the sodium-potassium pump. Nature 2007, 450, 1043. [CrossRef] [PubMed]

(C) 2018 by the authors. Licensee MDPI, Basel, Switzerland. This article is an open access article distributed under the terms and conditions of the Creative Commons Attribution (CC BY) license (http:/ / creativecommons.org/licenses/by/4.0/). 